\section{Alimentação escolar e constituição de identidades dos escolares: da merenda para pobres ao direito à alimentação}

\author{
School feeding and the establishment of school \\ identities: from meals for the poor to the \\ right to food
}

\section{Alimentación escolar y constitución de identidades entre escolares: de la merienda para pobres al derecho a la alimentación}

Edleuza Oliveira Silva 1,2

Lígia Amparo-Santos 2

Micheli Dantas Soares 1

doi: 10.1590/0102-311X00142617

\title{
Resumo
}

Este ensaio busca problematizar a alimentação escolar enquanto prática que contribui para a constituição de identidades escolares. Parte-se de uma revisão bibliográfica, não sistemática, de publicações sobre alimentação escolar e identidades no contexto das escolas públicas brasileiras. Discute-se, inicialmente, a persistência de discursos e práticas de caráter assistencialista que reduziam a alimentação escolar a uma comida para pobres, questão observada nos estudos. Os significados desse caráter assistencialista concorrem para o entendimento de que ele parece funcionar como um mecanismo de poder capaz de inscrever, nos escolares, uma identidade de pobreza e inferioridade. Esse entendimento é situado nas relações de poder existentes na escola, no exercício do poder disciplinar e seu potencial de produzir identidades, assim como nas práticas de resistência decorrentes desses poderes no contexto da alimentação escolar. Considera-se ainda que os escolares sejam agentes de seus próprios processos identitários, haja vista que, em sua relação com a alimentação escolar, evidenciam-se, além de processos de sujeição, também processos de resistência e de construção ativa de identidade alimentar, nos quais agregam o tradicional e o moderno, o local e o global, dentre outros aspectos. Mesmo que ambiguidades sejam percebidas nesse cenário, entende-se que são indícios de mudanças no paradigma do pensar e fazer a alimentação escolar, trazendo elementos para problematizá-la: de um lado, ainda como um dispositivo de manutenção das desigualdades sociais e, de outro, esforços e ações para propiciá-la como um direito e promotora de identidades emancipatórias.

Alimentação Escolar; Comportamento Alimentar; Segurança Alimentar e Nutricional; Assistência Social

\author{
Correspondência \\ E. O. Silva \\ Universidade Federal do Recôncavo da Bahia. \\ Av. Carlos Amaral 1015, Santo Antônio de Jesus, BA \\ 44574-490, Brasil. \\ edleuza@ufrb.edu.br \\ 1 Universidade Federal do Recôncavo da Bahia, Santo Antônio \\ de Jesus, Brasil. \\ 2 Universidade Federal da Bahia, Salvador, Brasil.




\section{Introdução}

O termo "alimentação escolar" tem sido utilizado para denominar o conjunto de refeições ofertadas pelo Programa Nacional de Alimentação Escolar (PNAE). Desse modo, a alimentação escolar constitui uma prática alimentar relevante nas escolas públicas brasileiras de ensino fundamental e médio. $\mathrm{O}$ ato de comer na escola se realiza em meio a outras práticas que compõem o espaço escolar, configurando-se em experiências e processos que influenciam na construção de hábitos alimentares e de identidades de crianças e adolescentes.

O PNAE tem como objetivo contribuir para o desenvolvimento biopsicossocial, o rendimento escolar e a formação de hábitos alimentares saudáveis dos escolares, por meio de ações de educação alimentar e nutricional e oferta de refeições que atendam às suas necessidades nutricionais durante a sua permanência na escola 1 . O orçamento do programa, em 2010, foi de três bilhões de Reais para uma cobertura de 47 milhões de estudantes 2 , constituindo uma das principais políticas de alimentação e nutrição no Brasil. Todavia, sua longa trajetória foi constituída em meio a diversas e divergentes intencionalidades.

Santos et al. 3, ao percorrer o histórico do PNAE, marcou seus principais percursos. O programa foi criado em 1950, sob o nome de Campanha Nacional de Merenda Escolar (CNME), em um contexto de programas de combate à desnutrição, tomando uma conotação de um programa de suplementação alimentar para escolares de baixa renda. Agrega-se o fato de ter sido implementado, desde o início, sob a égide dos interesses da indústria de alimentos, inicialmente, servindo de escoamento dos excedentes da produção americana e, em seguida, com uma forte ligação com a indústria de alimentos brasileira.

Tal situação permitiu a predominância, durante décadas, de alimentos formulados nos cardápios escolares. Na década de 1970, durante o II Programa Nacional de Alimentação e Nutrição (PRONAN II), a CNME foi renomeada como Programa Nacional de Merenda Escolar, sendo um dos programas mais abrangentes. No entanto, sua gestão era centralizada e burocrática. Já na década de 1980, iniciase um processo de descentralização, conferindo maior autonomia aos municípios. Somente a partir da década de 1990, a elaboração de refeições mais compatíveis com os hábitos alimentares regionais foi normatizada, iniciando um estímulo à aquisição de alimentos básicos e in natura de produtores locais e o enfrentamento do domínio dos alimentos formulados 3 . Esses percursos sinalizam uma transição de uma cultura assistencialista e clientelista em torno da alimentação escolar e também de ações para transformá-la em direito.

O início do século XXI marca um novo cenário político no Brasil, no qual, a Segurança Alimentar e Nutricional foi alçada como prioridade de governo. Em 2003, o Conselho Nacional de Segurança Alimentar é reativado 4 , sendo um órgão articulador entre governo e sociedade civil, possibilitando interlocução e legitimidade aos movimentos sociais e à militância política de intelectuais e pesquisadores na luta pelo Direito Humano à Alimentação Adequada e Saudável (DHAA) para todo brasileiro. Como importantes marcos políticos, destacam-se a promulgação, em 2006, da Lei Orgânica de segurança alimentar nutricional e a criação do Sistema Nacional de Segurança Alimentar e Nutricional (SISAN), no qual, o PNAE integra como uma das estratégias de garantir o DHAA nas escolas 5. E, em 2010, finalmente, a alimentação inscreve-se como um direito social no Brasil, por meio da Emenda Constitucional no 64/20106, a ser garantido por um conjunto de ações intersetoriais que compõem o SISAN. O PNAE também ganha um marco regulatório em 2009, sendo estruturado como uma política de segurança alimentar nutricional 1, iniciando um importante processo de mudança de paradigma.

Atualmente, o PNAE é uma política reconhecida mundialmente, sendo referência para implantação de programas de alimentação escolar sustentáveis em outros países e, portanto, não resta dúvida de que os avanços ocorridos concorrem para melhores condições de aprendizagem e de permanência dos alunos na escola. Entretanto, ainda que se leve, em consideração, a conquista da alimentação escolar alçada como direito humano, importa refletir sobre as ambiguidades que têm marcado as práticas em torno da alimentação escolar no cotidiano das escolas brasileiras, nesse contexto de mudança. Isso porque se tem observado a coexistência de esforços para propiciar uma alimentação digna com discursos e práticas de caráter assistencialista que associa os escolares que consomem a alimentação escolar a uma identidade de pobre e necessitado 7,8,9,10,11. 
Parte-se do entendimento de que as práticas alimentares participam dos processos identitários, pois a alimentação assume uma posição central no aprendizado e na formação social, por sua natureza vital, rotineira, geradora de sociabilidades e possibilidades de escolhas ${ }^{12}$. Para Poulain ${ }^{13}$, um alimento é incorporado tanto no plano físico quanto no simbólico, ou seja, não cumpre apenas a função de nutrir mediante suas propriedades sensoriais e nutricionais, mas produz prazer, promove prestígio, inclusão e distinção social, mediante suas propriedades simbólicas, e ainda, por outro lado, segundo Contreras \& Arnaiz 14 pode produzir sofrimento, privação e humilhação. Ou seja, as práticas alimentares não são apenas expressões ou recursos de afirmação de identidades, mas se inscrevem nos próprios processos identitários 13,15 .

A discussão sobre processos identitários adquire maior relevo na sociedade contemporânea, em virtude das mudanças resultantes da crise das estruturas sociais, das tradições e dos paradigmas 16,17,18. A identidade diz respeito a processos de individuação e identificação, resultantes de interações sociais e relações de poder entre indivíduos, situações e contextos 18,19, ao passo que também abarca a construção de vínculos e necessidades de reconhecimento e visibilidade 20 .

Assim, no âmbito da discussão deste ensaio, pretende-se construir um diálogo entre duas categorias complexas de estudo - processos identitários e práticas alimentares em torno da alimentação escolar. Nesse sentido, não se pode escapar da discussão dos processos identitários do escolar como, por exemplo, a identidade de ser aluno, que, por seu turno, implica no desejo pela escolarização e de pertencimento à comunidade escolar, o que não é dado apenas pela condição de aluno, mas envolve submissão às normas e aos padrões escolares 21,22 .

Por outro lado, processos identitários envolvem práticas e interações permeadas por relações de poder que podem significar a construção de identidades desejadas e valorizadas, assim como de identidades inferiorizadas que limitam ou privam o acesso a bens sociais que, por sua vez, levam a processos de resistência e luta por outras identidades 16,18,19.

Assim, este ensaio busca problematizar a alimentação escolar enquanto prática que contribui para a constituição de identidades escolares. Para tanto, foram feitas uma busca e análise de publicações sobre alimentação escolar no contexto das escolas públicas brasileiras, além de estudos sobre práticas alimentares e identidade.

Assim, realizou-se uma revisão bibliográfica, não sistemática, sem recorte temporal, por meio das bases de dados Scopus, Web of Science, PubMed, LILACS e SciELO, bem como em outras bases disponíveis como o Catálogo de Teses e Dissertações da Coordenação de Aperfeiçoamento de Pessoal de Nível Superior (Capes), além de livros que tratassem sobre o tema. Foram utilizados como termos de busca: "school feeding", "school eating", "school food", "school lunch", "school meal" "refeição escolar", "merenda escolar", "alimentação escolar") e "identity" ("identidade") em suas possíveis combinações. Foram usados como critério de seleção, a partir da leitura de títulos e resumos, estudos empíricos que incluíram, em seus objetivos ou resultados, a análise de práticas, percepções, representações e significados sobre a alimentação escolar, seja de estudantes ou de outros atores da comunidade escolar ou da gestão do PNAE. Foram selecionadas sete publicações brasileiras 7,8,9,10,11,23,24, às quais foram agregadas mais nove, identificadas a partir das próprias referências dessas publicações e também de buscas exploratórias, que, embora não mencionassem a temática de identidades, discutiram significados e práticas sobre a alimentação escolar que dialogavam com a constituição de identidades escolares 25,26,27,28,29,30,31,32,33. A busca também permitiu identificar seis estudos sobre refeições escolares em outros países que permitiram um diálogo com o contexto do PNAE 20,34,35,36,37,38. Outros estudos sobre identidade 16,18,19,39,40, PNAE 2,3,41, práticas alimentares e identidade 13,15, práticas escolares e identidade 21,22,42,43, também foram utilizados, assim como documentos e páginas eletrônicas do governo brasileiro.

Entendendo que o escopo do tema incide sobre práticas alimentares de escolares no contexto do PNAE, cabe fazer breves considerações sobre os 16 estudos selecionados que apresentaram elementos capazes de dialogar com a temática de processos identitários de escolares. Os estudos, ainda que com objetivos distintos, permitiram delinear um conjunto de discursos e práticas de alunos, merendeiras, professores, diretores e nutricionistas que revelaram significados e representações sociais sobre a alimentação escolar praticada em instituições públicas da Educação Básica. Os contextos foram escolas públicas da capital e interior do Rio de Janeiro 8,11,33, da capital e interior de São Paulo 23,26, da capital 
do Ceará 25, da capital e interior da Bahia 7,9,10,24,27,28,29,30, da capital de Goiás 32 e do interior dos estados do Pará, Piauí, Goiás, Minas Gerais e Santa Catarina 31. Os estudos se concentram no período de 2005-2016, convergindo com o recente momento de reestruturação do PNAE e criação da política de segurança alimentar e nutricional.

Discute-se sobre as relações de poder no espaço escolar e seu potencial de influenciar na construção de identidades escolares, e, em seguida, em plano interpretativo, apresenta-se uma reflexão sobre processos identitários que podem ocorrer em torno da alimentação escolar praticada na escola, que foram denominados de: processos de sujeição, de resistência e de identificação. Reitera-se que os 16 estudos não são representativos da realidade da alimentação escolar no Brasil, entretanto, na medida em que trazem questões sobre alimentação escolar e identidades, que encontram ressonância com a trajetória da política de alimentação escolar, apontam questões sociais significativas que demandam reflexão.

\section{Discursos e práticas em torno da alimentação escolar praticada no cotidiano da escola}

A alimentação escolar, como realização do DHAA nas escolas, materializa-se, entre outras ações, pela garantia da oferta de refeições produzidas a partir dos princípios da alimentação saudável, valorizando costumes regionais e uso de alimentos oriundos da agricultura familiar; pelas ações de educação alimentar e nutricional e pela criação de Conselhos de Alimentação Escolar estaduais e municipais que possibilitam a participação da sociedade civil na política do PNAE 1. Embora seja uma árdua conquista, o arcabouço jurídico-normativo e resoluções operacionais não têm sido suficientes para sua realização e apropriação plena como direito. Entende-se que, no decorrer de décadas de existência do programa, formou-se uma cultura clientelista e assistencialista. A transformação dessa realidade para o desenvolvimento de uma cultura de direitos a ser desenvolvida pela política de segurança alimentar e nutricional fundamentada no DHAA requer a instituição de novas práticas e novas institucionalidades 44. Assim, o momento presente traduz-se em um período de transição marcado por esforços, avanços, resistências e ambiguidades em torno da alimentação escolar praticada no cotidiano das escolas.

Nesse contexto, percebe-se que o assistencialismo, enquanto prática e discurso, ainda se perpetua no âmbito da alimentação escolar, entendendo-se que se imbrica com questões ideológicas, econômicas e políticas em torno do PNAE, e também da escola pública, ao longo de sua história. Destaca-se que os próprios autores dos estudos 7,8,9,10,11,23,25,26,27,28,29,32 interpretaram que os discursos dos entrevistados, sejam alunos, professores, merendeiras, diretores e nutricionistas, expressavam representações de conotação assistencialista sobre a alimentação escolar. Como também identificaram, a partir da observação do cotidiano da escola, a existência de práticas assistencialistas. Ressalta-se que esses estudos se situam em um pequeno e recente intervalo de tempo (2005-2016), portanto, representa o momento de mudança, visto que, somente a partir do ano de 2009, o PNAE é reestruturado, normativa e operacionalmente, como parte da política de segurança alimentar e nutricional, ainda que lutas e avanços tenham ocorrido ao longo de sua trajetória.

A interpretação dos autores foi explicada a partir de diversos significados sobre o caráter assistencialista que recai sobre a alimentação escolar, a saber: produz um habitus - no sentido bourdieusiano, estruturas estruturadas e estruturantes 45 - com poder de orientar as práticas relacionadas ao comer na escola, à organização do trabalho pedagógico e à jornada escolar 25; reduz a alimentação escolar a uma suplementação nutricional 8,23,25,26,28,32; traduz a alimentação escolar como uma doação aos estudantes mais pobres, estabelecendo uma relação de poder sobre quem a recebe 11,27,28; dificulta o reconhecimento da alimentação escolar como direito de todos os escolares, não apenas para os mais pobres, contribuindo para situações de privação, discriminação e exclusão 10,11,25; dificulta a participação de pais e escolares na definição do cardápio e de reconhecer suas preferências e gostos 8,25,26.

Esses significados instigam a interrogar se esse caráter assistencialista funciona como um mecanismo de poder capaz de inscrever, nos escolares, uma identidade de pobre e necessitado. Conquanto, importa distinguir assistência de assistencialismo. Considera-se que ações assistenciais sempre serão necessárias quando há violação ou privação de direitos. A assistência, vale ressaltar, está relacionada à obrigação estatal de prover direitos, mediante políticas públicas que assegurem a dignidade humana. 
Ao mesmo tempo, a assistência se constitui em uma parceria entre poderes públicos e comunidade, possibilitando participação e recursos para a emancipação. Por sua vez, o assistencialismo distorce a ação assistencial, insinuando uma condição de retribuição à ação proporcionada. E, por isso, constitui-se em uma prática de dominação, produzindo corpos dóceis e manipuláveis 46 .

No âmbito das escolas, as relações e mecanismos de poder estão atrelados a vários tipos de hierarquias, as quais possuem o poder de influenciar as escolhas, as opiniões e a própria percepção dos estudantes sobre si próprios e, portanto, influenciar em seus processos identitários e nas suas percepções sobre a alimentação escolar. Assim, professores e funcionários, em suas interações cotidianas com crianças e adolescentes, desenvolvem, entre si, relações que podem ser constituídas de cuidados, afetos, admiração ou de dominação, influenciando processos identitários e formativos, isto é, em crenças, valores, hábitos, comportamentos e práticas.

Nesse contexto escolar, os professores representam um sistema de poder - o sistema educacional, o conhecimento - e, portanto, são agentes com poder de definir e determinar identidades 43,47 . Por exemplo, quando professores expressam representações sobre a alimentação escolar, associando seu consumo à condição de pobreza, podem estar contribuindo para legitimar uma identidade estigmatizada, desvalorizada e não desejada 11 , visto que a identidade de ser pobre está associada a estigma, exclusão e culpabilização dos próprios sujeitos por sua condição de pobreza 48. Influências como essas podem contribuir para inscrever, em crianças e adolescentes, a naturalização de identidades de sujeição às estruturas de poder e de submissão às condições de pobreza e desigualdade.

Entretanto, crianças e adolescentes não são passivos em suas relações com outros sujeitos e estruturas sociais, eles são agentes de seus próprios processos identitários e práticas alimentares. Por exemplo, no ambiente familiar, crianças de camadas populares participam das escolhas relacionadas às compras de gêneros alimentícios da família 49 . No ambiente escolar, mesmo os estudantes mais pobres podem não aceitar a alimentação ofertada, conforme relata um dos estudos, no qual se observou que o consumo da alimentação escolar não dependia apenas da renda familiar, visto que, no estrato mais pobre, a aceitação estava em torno de $68,7 \%$ e, no estrato de maior renda, de $44,2 \% 31$. Tal fato corrobora com a reflexão sobre a interação dos processos identitários dos alunos em sua relação com a alimentação escolar.

Outros estudos relatam ações de rejeição, brincadeiras e desperdício com as refeições servidas, além de sentimento de indignação por não participarem da elaboração dos cardápios 10,27,28,29. São situações que podem significar resistência ao uso da alimentação escolar como um instrumento de dominação e controle sobre os escolares, de legitimação de identidades subalternas.

Essas práticas e discursos sinalizam que a alimentação escolar, ao se materializar em refeições que compõem o cotidiano da escola, além de cumprir funções de alimentar e nutrir, comunica significados que constituem, de modo diverso, as identidades dos que dela participam.

\section{Alimentação escolar e constituição de identidades de sujeição, de resistência e de identificação}

Admite-se que processos identitários, sejam de escolares ou de qualquer outra categoria, não sejam fáceis de serem identificados e caracterizados, pois identidades são múltiplas, transitórias e contingentes. Reitera-se que identidade diz respeito à necessidade de reconhecimento e pertencimento social, ou seja, construção de vínculo entre indivíduo e sociedade 18, e, por isso, para crianças e adolescentes, a escola representa um espaço social importante para essa construção. Entretanto, esse espaço pode contribuir na construção de identidades emancipadoras ou apenas formar corpos dóceis para uso das estruturas de poder. Assim, cabe analisar como a alimentação escolar tem contribuído para esses processos.

A partir do contexto de esforços de consecução da alimentação escolar como direito, mas permeado ainda por discursos e práticas assistencialistas, tenta-se elucidar processos de sujeição, de resistência e de identificação dos estudantes em relação à alimentação escolar praticada na escola.

Mesmo com a melhoria dos níveis de segurança alimentar e nutricional da população brasileira, mesmo que a Organização das Nações Unidas tenha declarado que o Brasil saiu do Mapa Mundial da Fome em 2014 50, escolares das camadas populares ainda convivem com os constrangimentos de 
ordem socioeconômica, instando-os a processos de sujeição tais como, se um aluno estiver faminto na escola e se deparar com uma preparação da alimentação escolar que não lhe agrada, a fome poderá impeli-lo a comer mesmo assim ${ }^{30}$. Sendo assim, importa discutir como se dão esses processos de sujeição.

Em um contexto mais geral, alguns estudos relatam práticas variadas dos alunos em relação à alimentação escolar: uma parte consome apenas a alimentação fornecida pela escola; outros comem esporadicamente, dependendo das suas preferências e das condições em que a refeição é ofertada; outros recusam e nunca comem 7,26,27,29. Ressalta-se que escolhas e práticas também variam de acordo com a situação socioeconômica dos alunos, variações que Oliveira \& Santos 29 chamaram de "escala dos níveis de pobreza”: aqueles que tinham dinheiro para comprar uma merenda; aqueles que levavam merenda de casa; aqueles que consumiam a merenda escolar. Tais situações colocam a alimentação escolar também como um dispositivo de produção da diferença, construto inerente a processos identitários, mas, nesse caso, ela parece contribuir para classificar e inferiorizar aqueles que a consomem, haja vista relatos de situações em que escolares comem a alimentação escolar mesmo sem gostar, em um silêncio que comunica um constrangimento frente à impossibilidade de recusar, por não terem alternativas para se alimentar 28 , situações também interpretadas com um consumo satisfeito e resignado ${ }^{29}$, ou como um esforço de vencer a vergonha e o limiar do que não era aceito ${ }^{30}$. Somam-se a esses relatos de constrangimento, as situações de privação, quando o aluno prefere ficar sem comer nada a ser identificado como pobre e necessitado se consumir a alimentação escolar 11 .

Essas são situações que podem ser entendidas como efeitos do uso da alimentação escolar como dispositivo de poder, revelado também nas representações sociais sobre a alimentação escolar presentes nos discursos de professores e merendeiras, tais como "obrigação; necessidade; o governo dá, e o aluno tem que receber; não precisa ter gosto” 28 (p. 42). Por isso, importa pensar que repercussões têm essas representações nas identidades dos escolares, pois parecem constituir processos de sujeição vivenciados cotidianamente ao longo de sua trajetória escolar, misturada aos esforços de ter sucesso em seus processos de escolarização e reconhecimento social, que, por sua vez, lhes colocam permanentemente em condições de submissão às normas da escola ou de subversão. São situações que integram uma teia de relações de poder inerente à escola, por ser ela mesma uma instituição de exercício do poder disciplinar que alcança a todos que a constituem. Conforme Foucault 51, o poder disciplinar diz respeito às formas de controle dos sujeitos por meio da disciplina, ou seja, mecanismos que, ao mesmo tempo, tornam-os obedientes e úteis às estruturas de poder.

A saber, de um lado, os professores encarregados em fazer cumprir um currículo por meio de práticas escolares que produzam uma escolarização padronizada, definida por instâncias supranacionais que conjugam políticas educacionais com políticas econômicas 42 , de outro, os escolares em intenso processo de construção de identidades, buscando reconhecimento e construção de vínculo social. Ambos, professores e escolares, constituindo-se agentes que interagem em um espaço social que lhes permite, ou não, o uso de recursos para atingir os seus objetivos. Nesse contexto, a alimentação escolar, além de um direito, constitui-se um recurso de poder, porém, à mercê de apropriações ou desapropriações moduladas por quem tem mais poder.

Entretanto, onde há poder, há resistência 51 . Processos de resistência em torno da alimentação escolar estão associados a reações a significados que desvalorizam tanto a alimentação escolar como o aluno que a consome. E situações concretas que afrontam a dignidade humana, tais como refeições produzidas e distribuídas em condições higiênicas inadequadas, também produzem processos de resistência. Como exemplos, temos o uso de colher e prato plásticos para escolares, sejam crianças ou adolescentes, submetendo-os a comportamentos infantilizados, ou ainda a ausência de refeitórios, obrigando os escolares a comerem em pé, andando ou sentados no chão. Atrelam-se a essas questões do comer na escola, os constrangimentos da sua estrutura física, como a existência ainda de escolas com muros altos e portões de estrutura compacta que as equiparam a presídios, além de outras situações descritas em vários estudos 25,28,29,30. Assim, processos de resistência se constituem como reação às representações sociais da alimentação escolar como uma comida para pobres, traduzida em práticas e estruturas 27 , abarcando também a própria escola como uma estrutura de reprodução de identidades subalternas.

Pode-se inferir também, como processos de resistência, as práticas de trazer alimentos para a escola, comprar alimentos da cantina ou de vendedores próximos ao entorno da escola ou ficar sem 
comer 7,10,25,26. Essas situações trazem, para discussão, o direito à escolha no contexto do DHAA na escola. Estudos mostram se tratar de uma equação difícil de solucionar entre permitir opções e, ao mesmo tempo, não produzir discriminações. A exemplo do contexto estadunidense, foi visto que tanto a restrição de opções no próprio cardápio do Programa Nacional de Almoço Escolar dos Estados Unidos (National School Lunch Program - NSLP) quanto a existência de alternativas alimentares, como cantinas particulares no interior da escola, têm contribuído para processos de estigmatização de escolares 37,38. E por sua vez, produzem práticas de resistências, como descreve Nukaga 34, em um estudo com escolares imigrantes de origem coreana em duas escolas públicas americanas, situadas em um bairro de classe média, em que eles traziam refeições de casa com características étnicas e ainda realizavam trocas entre si. O autor interpretou essas práticas como formas de construção de identidades e marcação das diferenças em meio à homogeneização cultural produzida pela oferta de refeições padronizadas pelo NSLP, uma política que também possui uma relevância social, mas tem sido questionada em suas práticas no cotidiano escolar 37.

Retomando ao contexto das escolas públicas brasileiras, outros processos de resistência são observados diante de situação de rejeição a certas preparações como o mingau e a sopa, provocada não apenas pelo sabor, aparência, horário, mas também porque os escolares as associam à alimentação de bebês e idosos 10, um comportamento que pode significar marcação da diferença e empenho dos escolares na construção de identidades compatíveis com sua idade, com seu grupo social. Outros pratos regionais, como arroz-doce e o mungunzá, podem estar associados a um possível baixo status social 10 . Assim, se a alimentação escolar é composta de alimentos de baixo status social pode comunicar uma identidade de pobreza a quem a consome ${ }^{8}$. Enfim, as recusas, a compra de outras merendas, o desperdício e até mesmo ficar sem comer podem representar processos de resistência ao uso da alimentação escolar como dispositivo de dominação e necessitam ser analisados à luz de uma cultura de direitos, considerando, nesse bojo, a dinâmica da cultura alimentar.

Salienta-se que a cultura alimentar de uma dada comunidade é um processo dinâmico de trocas entre o local e o global e, por conseguinte, afetada por processos de homogeneização da cultura alimentar promovida pela globalização. E, nesse contexto, hábitos alimentares regionais, por vezes, são considerados anacrônicos, enquanto que certo conjunto de produtos industrializados e globais é associado à modernidade, à juventude, dessa forma, conferindo baixo status social aos alimentos regionais. Todavia, como efeito reverso da própria globalização da alimentação, surgem movimentos de resistência e de interesse em preservar e fomentar a agricultura local e valorizar a cultura alimentar regional 9 .

Nessa esteira, destaca-se que, em meio a processos de sujeição e resistências, também se pode perceber a contribuição da alimentação escolar na formação de uma cultura identitária alimentar, haja vista que os esforços em ofertar alimentos saudáveis e regionais pelo PNAE representam um avanço importante em comparação às décadas iniciais do programa, em que predominavam alimentos industrializados e "estranhos" à cultura alimentar 9 .

Nesse contexto, é que se destacam, sob o ponto de vista da política pública, dispositivos no arcabouço jurídico-normativo que contribuem para a formação de uma cultura identitária. A Lei no 11.947/2009 1 estabelece que os cardápios da alimentação escolar devam ser elaborados com gêneros alimentícios básicos e que, no mínimo 30\%, sejam adquiridos da agricultura familiar e de suas organizações, respeitando não só as referências nutricionais, mas também a cultura alimentar da localidade 1 . Com efeito, em 2010, 47,4\% dos municípios brasileiros compraram alimentos da agricultura familiar, alcançando uma média de 22,7\% de recursos aplicados nessa aquisição, considerada significativa para o primeiro ano em que a lei passou a vigorar 41. Destaca-se também que a Resolução no 38/2009 52 torna obrigatório servir frutas e verduras no cardápio semanal da alimentação escolar.

As aquisições provenientes da agricultura familiar buscam associar-se aos hábitos alimentares dos brasileiros, em suas diversas matizes, conforme a região, pois é ela que produz e contribui com um volume significativo dos alimentos básicos como a farinha de mandioca, o feijão, o milho, o café, o arroz, o leite, as carnes e o trigo 41. Cabe salientar que o incentivo à compra de gêneros da agricultura familiar ainda propicia a inclusão de alimentos não habituais produzidos na região como, por exemplo, o iogurte, considerado, ao mesmo tempo, saudável e símbolo da modernidade e, ainda que não faça parte do hábito alimentar das classes populares, possui boa aceitação pelos escolares ${ }^{10}$, possivelmente pelo status social conferido pela publicidade da agroindústria. 
Nesse contexto, chama a atenção a preferência de escolares por preparações salgadas, incluindo comidas típicas à base de arroz e feijão, relatadas em um estudo que envolveu 55 municípios baianos 27 . Assim, ainda que os estudantes considerem estranho servirem preparações com características de almoço ou jantar na hora da merenda, 10 horas da manhã e 3 horas da tarde 7 , possivelmente, a preferência por essas preparações está associada à cultura alimentar local e nacional, construída desde a infância, que ainda persiste, mesmo com a inclusão de novos alimentos da modernidade. Considera-se ainda que a mistura feijão com arroz constitui um símbolo identitário da cultura alimentar brasileira 40, é uma comida conhecida, familiar, consagrada pela cultura e que resulta em convergência do prazer sensorial com o prazer de comer a mesma comida, partilhando a mesma identidade.

Todavia, para um escolar, comer uma comida de almoço ou jantar na hora da merenda também pode representar ainda situações de pobreza, em que se aceita a merenda como um mini almoço ou mini jantar. Pode-se também considerar que essa aceitação é favorecida pelas mudanças da alimentação na contemporaneidade, a exemplo da flexibilização das refeições, inclusive dos horários 13 , situação que pode ser vista com naturalidade por adolescentes. Assim, as refeições do PNAE podem produzir reações diversas, em um momento, produzir o estranhamento, que pode levar à rejeição, em outro, a aceitação pela familiaridade e identificação com a preparação, propiciando a comensalidade e o desfrute de uma comida típica.

Em outra direção, escolares de dois municípios baianos preferem mais refeições do tipo biscoito com suco 10,30. Nesse caso, pode-se observar uma aproximação das características da refeição ao que os escolares consideram, de fato, uma merenda, rápida e leve, que não atrapalhe brincar durante o recreio 7,10 . Isso se deve ao fato de que preferências alimentares dos escolares podem estar associadas à publicidade de um conjunto de alimentos reconhecidos como marca identitária de um estilo de "ser jovem", denominados de "besteiras", que incluem preponderantemente produtos industrializados como biscoitos, refrigerantes, hambúrguer, cachorro-quente, pizza, sorvete, salgados, doces, chocolate, batata frita, achocolatados, nuggets, entre outros 53 . Ainda se deve levar em conta que vários produtos industrializados já fazem parte do hábito alimentar do brasileiro, a exemplo dos biscoitos doces e salgados 54,55, como resultado do desenvolvimento das indústrias de alimentos ocorrido na primeira metade do século XX. Diferentemente do início do PNAE, nos anos 1950, em que predominavam os formulados oriundos da indústria americana, na atualidade, os alimentos industrializados não causam estranhamento. Ao contrário, são símbolos de modernidade e praticidade, amplamente promovidos pela publicidade, conferindo status social.

Santos \& Soares 56 apontam a necessidade de buscar compreender como se dá a construção de significados em torno dos produtos alimentícios e suas marcas, assim como das estratégias de identificação dos sujeitos a elas. Nessa direção, Andrade 24 observou que as escolhas alimentares de escolares adolescentes de uma escola pública em Salvador, Bahia, são determinadas pela fome, prazer e gosto, mas fortemente associadas às necessidades de visibilidade, de convívio social e de pertencimento. Semelhantemente, ainda que seja outra realidade, mas considera-se haver similaridades nos processos identitários de escolares, Stead et al. 35 apontaram que as escolhas alimentares de escolares adolescentes de duas escolas públicas inglesas levavam, em conta, o status social e a popularidade das marcas dos alimentos, e escolhas que representem danos à própria imagem perante seus grupos sociais podem ser prejudiciais ao escolar.

Em uma direção semelhante, Vargas et al. 33, em um estudo de intervenção visando à prevenção de obesidade em escolares de duas escolas públicas em Niterói, Rio de Janeiro, relataram que alunos que referiram gostar de frutas e verduras foram veementemente contestados por outros colegas que enfatizavam suas preferências por alimentos tidos como não saudáveis. O estudo sinaliza interfaces entre necessidades de pertencimento social, construção identitária, publicidade e formação de hábitos alimentares de adolescentes.

Isso instiga a refletir sobre o poder da publicidade na formação das práticas alimentares e como isso é traduzido na relação dos estudantes com a alimentação escolar. Assim, preferências por preparações regionais e também por alimentos propagados pela mídia não necessariamente expressam ambiguidades nos processos identitários dos escolares, e sim uma aderência às tendências das práticas alimentares na modernidade, caracterizada, entre outras coisas, pela flexibilização, e que, de certa forma, a alimentação escolar contribui nesse processo. Ressalta-se que a coexistência de identificação com alimentos da cultura alimentar nacional e com alimentos que ultrapassam as fronteiras culturais 
se nota em outros contextos escolares com programas de alimentação escolar. Theodore et al. ${ }^{36}$, ao estudarem, na Cidade do México, representações sobre a alimentação em escolas beneficiárias de um programa de refeições escolares, identificaram que os escolares, ao mesmo tempo, revelavam um caráter identitário mediante o gosto e o prazer pelas comidas tradicionais como tacos, tortilhas e tamales, como também pelo consumo de alimentos globalizados como a pizza e o refrigerante.

Assim, as ambiguidades percebidas na relação dos escolares com a alimentação escolar são indícios de mudanças, traduzidos em processos de identificações, expressadas pelo consumo de preparações de suas preferências, reunindo o regional e o global, em processos de sujeições ante a necessidade de se alimentar frente à restrição de alternativas e em processos de resistências que comunicam o desejo de "ser mais", como dizia Paulo Freire 57, ao se referir ao processo de enfrentamento social e político da condição de pobreza como uma relação de opressor-oprimido.

\section{Considerações finais}

A discussão da alimentação escolar como um elemento constitutivo de identidades escolares foi motivada pela problemática levantada em alguns estudos sobre a persistência de discursos e práticas de caráter assistencialista que reduziam a alimentação escolar à comida para pobres.

A alimentação escolar, ao ser instituída em meio a políticas de alimentação e nutrição como uma ação para minimizar a desnutrição, foi reduzida, por muito tempo, a uma ação assistencial focalizada para grupos vulneráveis socialmente, traduzidos, no senso comum, como uma comida para alunos pobres e necessitados. Todavia, sua instituição como um direito de todos os escolares, fruto de lutas e movimentos sociais redundaram em sua implementação como uma estratégia de segurança alimentar e nutricional fundamentada no DHAA.

Entretanto, a alimentação escolar se dá em um espaço de relações de poder historicamente legitimadas, também produtor de práticas e identidades, onde se percebe uma ressonância das práticas escolares com a prática da alimentação escolar. Ou seja, o papel ambíguo da escola, enquanto dispositivo de poder e sujeição e, ao mesmo tempo, de possibilidade de construção de identidades emancipatórias, também influencia na dinâmica da alimentação escolar como constitutiva de identidades.

Por sua vez, as ambiguidades percebidas, tanto na execução da alimentação escolar como nas práticas alimentares dos estudantes, dão indícios de mudanças no paradigma do pensar e fazer a alimentação escolar. Nesse contexto, emergem elementos para problematizar a alimentação escolar: de um lado, a existência de práticas que ainda a constituem como um dispositivo de conservação social e manutenção das desigualdades sociais, no sentido bourdieusiano e foucaultiano, e, de outro, esforços para propiciá-la como um direito possibilitam outros processos identitários para além da sujeição. Portanto, a alimentação escolar, apesar da persistência do assistencialismo, pode representar, para os escolares das classes populares, uma possibilidade de projetar outras identidades que não a subalterna, como processos de resistência às práticas de dominação e controle e processos de construção de identidade alimentar que agreguem criticamente o tradicional e o moderno, o local e o global.

Compreender a alimentação escolar como um constitutivo de identidades escolares pode instrumentalizar os sujeitos para questionar as identidades que as estruturas de poder querem legitimar e questionar o sistema de representação que lhes dá sustentação, como sinaliza Silva 47, além de contribuir para a construção de conhecimentos que possam instrumentalizar tanto o planejamento da política do PNAE como também os escolares e todos da comunidade escolar. Convém ressaltar que as práticas alimentares, incluindo a alimentação escolar, sendo constitutivas dos processos identitários, implicam em interações que também afetam a saúde do corpo, requerendo estudos que elucidem as interfaces entre práticas alimentares, identidades e saúde. 


\section{Colaboradores}

E. O. Silva e L. Amparo-Santos contribuíram na concepção, delineamento e escrita do ensaio. M. D. Soares colaborou no delineamento e revisão crítica.

\section{Agradecimentos}

À Fundação de Amparo à Pesquisa do Estado da Bahia pelo financiamento.

\section{Referências}

1. Brasil. Lei no 11.947 , de 16 de junho de 2009. Dispõe sobre o atendimento da alimentação escolar e do Programa Dinheiro Direto na Escola aos alunos da educação básica. Diário Oficial da União 2009; 17 jun.

2. Peixinho AML. A trajetória do Programa Nacional de Alimentação Escolar no período de 2003-2010: relato do gestor nacional. Ciênc Saúde Coletiva 2013; 18:909-16.

3. Santos LAS, Alves LA, Santos LS, Henrique FCS, Mazza RPD. Programa Nacional de Alimentação Escolar no contexto da municipalização. In: Santos SMC, Santos LMP, organizadores. Avaliação de Políticas de Segurança Alimentar e Nutrição no Estado da Bahia. 2a Ed. São Paulo: Prol Editora Gráfica; 2008. p. 185-226.

4. Brasil. Decreto no 4.582 , de 30 de janeiro de 2003. Regulamenta o funcionamento do Conselho Nacional de Segurança Alimentar e Nutricional - CONSEA, e dá outras providências. Diário Oficial da União 2003; 31 jan.

5. Brasil. Lei no 11.346, de 15 de setembro de 2006. Cria o Sistema Nacional de Segurança Alimentar e Nutricional - SISAN. Diário Oficial da União 2006; 18 set.

6. Brasil. Emenda Constitucional no 64, de 4 de fevereiro de 2010. Altera o art. 6o da Constituição Federal, para introduzir a alimentação como direito social. Diário Oficial da União 2010; 5 fev.

7. Freitas MCS, Minayo MCS, Ramos LB, Fontes GV, Santos LA, Souza EC, et al. Escola: lugar de estudar e de comer. Ciênc Saúde Coletiva 2013; 18:979-85.

8. Mielniczuk VBO. Gosto ou necessidade? Os significados da alimentação escolar no Município do Rio de Janeiro [Dissertação de Mestrado]. Rio de Janeiro: Universidade Federal Rural do Rio de Janeiro; 2005.

9. Paiva JB, Freitas MCS, Santos LAS. Hábitos alimentares regionais no Programa Nacional de Alimentação Escolar: um estudo qualitativo em um município do sertão da Bahia, Brasil. Rev Nutr 2012; 25:191-202.

10. Paiva JB, Freitas MCS, Santos LAS. Significados da alimentação escolar segundo alunos atendidos pelo Programa Nacional de Alimentação Escolar. Ciênc Saúde Coletiva 2016; 21:2507-16.

11. Portronieri FRDS. O jovem, o comer e o perceber-se: concepções de alunos e professores sobre o corpo, a alimentação e a saúde em uma escola municipal do Rio de Janeiro [Dissertação de Mestrado]. Rio de Janeiro: Universidade Federal do Rio de Janeiro; 2010.

12. Mintz S. Comida e antropologia. Uma breve revisão. Rev Bras Ciênc Soc 2001; 16:31-41.

13. Poulain JP. Sociologias da alimentação. Florianópolis: Editora da UFSC; 2004.

14. Contreras J, Arnaiz MG. Alimentação, sociedade e cultura. Rio de Janeiro: Editora Fiocruz; 2011. 
15. Fischler C. Food, self and identity. Soc Sci Inf Stud 1988; 27:275-92.

16. Bauman Z. Identidade: entrevista a Bendetto Vecchi. Rio de Janeiro: Jorge Zahar Editora; 2005.

17. Canclini NG. Culturas híbridas. Estratégias para entrar e sair da modernidade. 4a Ed. São Paulo: Edusp; 2011.

18. Hall S. A identidade cultural na pós-modernidade. 12a Ed. Rio de Janeiro: Lamparina; 2015.

19. Castells M. O poder da identidade. v. II. 8a Ed. São Paulo: Paz e Terra; 1999.

20. Andersen SS, Holm L, Baarts C. School meal sociality or lunch pack individualism? Using an intervention study to compare the social impacts of school meals and packed lunches from home. Soc Sci Inf Stud 2015; 54:394-416.

21. Baptista M, Freire S, Carvalho C, Freire A, Azevedo M, Oliveira T. Cursos de educação e formação: uma oportunidade para questionar práticas de sala de aula e reconstruir identidades escolares. Rev Ensaio 2011; 13:151-70.

22. Castro PA. Tornar-se aluno: identidade e pertencimento - um estudo etnográfico [Tese de Doutorado]. Rio de Janeiro: Universidade do Estado do Rio de Janeiro; 2011.

23. Assao TY. Alimentação escolar: percepções dos atores sociais das escolas de um município da região metropolitana de São Paulo [Tese de Doutorado]. São Paulo: Universidade de São Paulo; 2012.

24. Andrade MAP. Preferências alimentares entre adolescentes: estudo de caso em Salvador, Bahia [Dissertação de Mestrado]. Salvador: Universidade Federal da Bahia; 2009.

25. Bezerra JAB. Alimentação e escola: significados e implicações curriculares da merenda escolar. Rev Bras Educ 2009; 14:103-15.

26. Leme ACB, Philippi ST, Toassa EC. O que os adolescentes preferem: os alimentos da escola ou os alimentos competitivos? Saúde Soc 2013; 22:456-67.

27. Freitas MCS, Ramos L, Santos L, Pena P, Santos AC, Ferreira A et al. Direito à alimentação escolar: observações em escolas da Bahia. In: Freitas MCS, Amparo-Santos L, Fontes GAV, Ramos L, organizadoras. Narrativas sobre cuidado alimentar e o comer na escola. Salvador: EDUFBA; 2016. p. 217-32.

28. Freitas MCS, Fontes GAV. Alimentação na escola pública: um estudo com adolescentes em unidades de ensino de municípios baianos. In: Freitas MCS, Fontes GAV, Oliveira N, organizadoras. Escritas e narrativas sobre alimentação e cultura. Salvador: EDUFBA; 2008. p. 37-54.

29. Oliveira N, Santos SMC. Práticas alimentares na escola: um estudo de caso na cidade do Salvador. In: Freitas MCS, Amparo-Santos L, Fontes GAV, Ramos L, organizadoras. Narrativas sobre cuidado alimentar e o comer na escola. Salvador: EDUFBA; 2016. p. 233-46.
30. Agatte VC, Freitas MCS. Significados da alimentação escolar em uma escola pública de Areia Branca, município de Lauro de Freitas, Bahia. In: Freitas MCS, Amparo-Santos L, Fontes GAV, Ramos L, organizadoras. Narrativas sobre cuidado alimentar e o comer na escola. Salvador: EDUFBA; 2016. p. 53-68.

31. Sturion GL, Silva MV, Ometto AMH, Furtuoso MCO, Pipitone MAP. Fatores condicionantes da adesão dos alunos ao Programa de Alimentação Escolar no Brasil. Rev Nutr 2005; 18:167-81.

32. Camozzi ABQ, Monego ET, Menezes IHCF, Silva PO. Promoção da alimentação saudável na escola: realidade ou utopia? Cad Saúde Colet (Rio J.) 2015; 23:32-7.

33. Vargas ICS, Sichieri R, Sandre-Pereira G, Veiga GV. Avaliação de programa de prevenção de obesidade em adolescentes de escolas públicas. Rev Saúde Pública 2011; 45:59-68.

34. Nukaga M. The underlife of kids' school lunchtime: negotiating ethnic boundaries and identity in food exchange. J Contemp Ethnogr 2008; 37:342-80.

35. Stead M, McDermott L, MacKintosh AM, Adamson A. Why healthy eating is bad for young people's health: identity, belonging and food. Soc Sci Med 2011; 72:1131-9.

36. Theodore FL, Bonvecchio Arenas A, Blanco García I, Carreto Rivera Y. Representaciones sociales relacionadas con la alimentación escolar: el caso de las escuelas públicas de la Ciudad de México. Salud Colect 2011; 7:215-29.

37. Mortazavi M. Consuming identities: law, school lunches, and what it means to be American. Cornell J Law Public Policy 2014; 24:1-45.

38. Bhatia R, Jones P, Reicker Z. Competitive foods, discrimination, and participation in the National School Lunch Program. Am J Public Health 2011; 101:1380-6.

39. Silva TT. Identidade e diferença: a perspectiva dos estudos culturais. Petrópolis: Editora Vozes; 2000.

40. DaMatta R. O que faz o brasil, Brasil? Rio de Janeiro: Editora Rocco; 1986.

41. Saraiva EB, Silva APF, Sousa AA, Cerqueira GF, Chagas CMS, Toral N. Panorama da compra de alimentos da agricultura familiar para o Programa Nacional de Alimentação Escolar. Ciênc Saúde Coletiva 2013; 18:927-35.

42. Pacheco JA, Pereira N. Globalização e identidade no contexto da escola e do currículo. Cad Pesqui 2007; 37:371-98.

43. Moita Lopes LP. Identidades fragmentadas. A construção discursiva de gênero, raça e sexualidade em sala de aula. Campinas: Mercado das Letras; 2002. 
44. Burlandy L, Mattos R. A construção do campo da segurança alimentar e nutricional no Brasil e suas potencialidades para a consolidação de uma cultura de direitos. In: Schneider OF, organizador. Segurança alimentar e nutricional. Tecendo a rede de saberes. Rio de Janeiro: Editora DP et Alii; Fundação Carlos Chagas Filho de Amparo à Pesquisa do Estado do Rio de Janeiro; 2012. p. 21-42.

45. Bourdieu P. O senso prático. 2a Ed. Petrópolis: Editora Vozes; 2011.

46. Burity V, Franceschini T, Valente F, Recine E, Leão M, Carvalho MF. Direito humano à alimentação adequada no contexto da segurança alimentar e nutricional. Brasília: Associação Brasileira pela Nutrição e Direitos Humanos; 2010.

47. Silva TT. A produção social da identidade e da diferença. In: Silva TT, organizador. Identidade e diferença: a perspectiva dos estudos culturais. Petrópolis: Editora Vozes; 2000. p. 73-102.

48. Minnaert ACST. A feira livre sob um olhar etnográfico. In: Freitas MCS, Fontes GAV, Oliveira $\mathrm{N}$, organizadoras. Escritas e narrativas sobre alimentação e cultura. Salvador: EDUFBA; 2008. p. 129-48.

49. Soares MD, Trad LAB. Cenas e sentidos do cuidado alimentar de crianças no mundo cotidiano. In: Freitas MCS, Amparo-Santos L, Fontes GAV, Ramos L, organizadoras. Narrativas sobre cuidado alimentar e o comer na escola. Salvador: EDUFBA; 2016. p. 13-36.

50. Portal Brasil. Relatório indica que Brasil saiu do Mapa Mundial da Fome. http://www.brasil.gov.br/governo/2014/09/relatorio-indicaque-brasil-saiu-do-mapa-mundial-da-fomeem-2014 (acessado em 05/Jul/2017).
51. Foucault M. Microfísica do poder. 16a Ed. Rio de Janeiro: Edições Graal; 2001.

52. Ministério da Educação. Resolução/CD/ FNDE no 38, de 16 de julho de 2009. Dispõe sobre o atendimento da alimentação escolar aos alunos da educação básica no Programa Nacional de Alimentação Escolar (PNAE). Diário Oficial da União 2009; 17 jun.

53. Serra GMA, Araújo IS, Santos EM. Comer com os olhos: discursos televisivos e produção de sentidos na promoção da saúde nutricional de adolescentes. RECIIS (Online) 2012; 6:1-14.

54. Souza AM, Pereira RA, Yokoo EM, Levy RB, Sichieri R. Alimentos mais consumidos no Brasil: Inquérito Nacional de Alimentação 2008-2009. Rev Saúde Pública 2013; 47 Suppl $1: 190 s-9 \mathrm{~s}$.

55. Levy RB, Castro IRR, Cardoso LO, Tavares LF, Sardinha LMV, Gomes FS, et al. Consumo e comportamento alimentar entre adolescentes brasileiros: Pesquisa Nacional de Saúde do Escolar (PeNSE), 2009. Ciênc Saúde Coletiva 2010; 15 Suppl 2:3085-97.

56. Santos LAS, Soares MD. "Abrindo a felicidade": interações entre os discursos publicitário e saudável no campo da alimentação e nutrição. In: Ferreira FR, Freitas RF, Prado SD, Carvalho MCVS, organizadores. Consumo, comunicação e arte. Curitiba: Editora CRV; 2015. p. 259-74.

57. Freire P. Pedagogia do oprimido. São Paulo: Paz e Terra; 1997. 


\section{Abstract}

This essay aims to analyze school feeding as a practice contributing to the establishment of school identities. The point of departure is a nonsystematic review of publications on school feeding and identities in Brazil's public schools. The discussion begins with the persistence of paternalistic discourses and practices that reduce school feeding to food for the poor, observed in the studies. The meanings in this paternalistic approach suggest that it appears to function as a power mechanism to brand the schoolchildren with an identify of poverty and inferiority. This understanding is situated in the prevailing power relations in schools, in the exercise of disciplinary power and its potential to produce identities, as well as the practices of resistance resulting from such power in the school feeding context. The schoolchildren are also agents of their own identity processes, considering that their relations with school feeding involve processes not only of subordination but also of resistance and active identity-building, combining the traditional with the modern, the local with the global, among other aspects. Even the ambiguities in this scenario are signs of a paradigm shift in the planning and practice of school feeding, raising elements to analyze it: on the one hand, as a device for the maintenance of social inequalities, and on the other, efforts and actions to support school feeding as an essential right and factor for emancipatory identities.

School Feeding; Feeding Behavior; Food and Nutrition Security; Social Assistance

\section{Resumen}

Este estudio busca problematizar la alimentación escolar, como práctica que contribuye a la configuración de identidades escolares. Se parte de una revisión bibliográfica, no sistemática, de publicaciones sobre alimentación escolar e identidades en el contexto de las escuelas públicas brasileñas. Se discute, inicialmente, la persistencia de discursos y prácticas de carácter asistencialista, que reducian la alimentación escolar a una comida para pobres, cuestión observada en diversos estudios. El concepto de ese carácter asistencialista concurre hacia la comprensión del fenómeno y su interpretación, como un mecanismo de poder capaz de adscribir a los escolares una identidad de pobreza e inferioridad. Esta interpretación está imbricada en las relaciones de poder existentes en la escuela, en el ejercicio del poder disciplinario y su potencial de producir identidades, así como en las prácticas de resistencia, provenientes de esos poderes en el contexto de la alimentación escolar. Se considera incluso que los escolares sean agentes de sus propios procesos identitarios, a la vista que, en su relación con la alimentación escolar, se evidencian, además de procesos de subordinación, también procesos de resistencia y de construcción activa de identidad alimentaria, en los que se agrega lo tradicional y lo moderno, lo local y lo global, entre otros aspectos. A pesar de que se perciban ambigüedades en este escenario, se entiende que son indicios de transformaciones en el paradigma de la conceptualización y puesta en práctica de la alimentación escolar, llevando consigo elementos para problematizarla: por un lado, todavía, como dispositivo de soporte de las desigualdades sociales $y$, por otro, los esfuerzos y acciones para propiciarla como un derecho $y$ como promotora de identidades emancipadoras.

Alimentación Escolar; Conducta Alimentaria; Seguridad Alimentaria y Nutricional; Asistencia Social
Recebido em 17/Ago/2017

Versão final reapresentada em 12/Jan/2018

Aprovado em 02/Fev/2018 